\title{
Clinical management of drug resistant tuberculosis: A comprehensive review
}

\author{
Sonal Jain ${ }^{1}$, Arun Kumar² \\ ${ }^{1}$ Medical Writer and Reviewer, ${ }^{2}$ Associate Professor, Department of Biochemistry, Manipal College of Medical Sciences, Pokhara
}

\section{A B STRA C T}

Despite the introduction 40 years ago of the inexpensive and effective four-drug (isoniazid, rifampicin, pyrazinamide and ethambutol) treatment regimen, tuberculosis (TB) continues to cause considerable morbidity and mortality worldwide. This is because of development of drug resistance in tuberculosis strains, usually called as MDR/XDR-TB. Consequently, novel drugs and regimens for management of these drug resistant TB forms are emerging. Such regimens probably utilize both repurposed drugs and new chemical drugs. This article covers current concepts and recent advances in TB drug discovery and development. An updated review of the mechanisms of action and resistance of the main old and new anti-tuberculosis agents has been described. The consensus statements from RNTCP for management of MDR/XDR-TB have also been discussed.

Key words: Amikacin, Capreomycin, Direct observed therapy-short course, Drug resistance tuberculosis, Isoniazid, Kanamycin, Minimum inhibitory concentration, Multi drug resistance tuberculosis, Open reading frame, Pyrazinamide, Rifampicin, Revised national TB control programme, South east, Extensively drug resistance tuberculosis
Access this article online

Website:

http://nepjol.info/index.php/AJMS

\section{TB EPIDEMIOLOGY}

Tuberculosis (TB) remains a major health problem and is associated with significant morbidity and mortality. ${ }^{1}$ Though a continued decrease in the rate of new TB cases has been reported globally during the last decade, the rate of decline $\left(2 \%\right.$ per year) remained slow. ${ }^{1}$

\section{Global load of disease ${ }^{1}$}

- Of the 8.6 million people who developed TB in 2012, 1.1 million (13\%) were HIV-positive.

- Approximately 4, 50000 people developed MDRTB and around 1, 70000 deaths from MDR-TB in the year 2012 have been reported.

- 530000 TB cases among children $<15$ years of age and 74,000 TB deaths (among HIV-negative children) have been reported in 2012. This lead to $6 \%$ and $8 \%$ of the deaths globally, respectively.

- Most of the cases were in the SE Asia (29\%), African (27\%) and Western Pacific (19\%) regions. India and China alone accounted for $26 \%$ and $12 \%$ of total cases, respectively in the year 2012 .
2. Incidence, Prevalence, Mortality in India ${ }^{2}$

- India has more new TB cases annually than any other country. Out of the 9 million TB cases globally, 2.3 million were estimated to have occurred in India in the year 2011 (Table 1).

\section{MULTI-DRUG RESISTANT TB (MDR -TB)}

Multidrug-resistant tuberculosis (MDR-TB) is defined as resistance to INH and RIF (first line drugs for treatment of TB), with or without resistance to other anti-TB drugs. ${ }^{3}$

\section{Prevalence of MDR -TB}

\section{Global Prevalence of MDR-TB ${ }^{4}$}

- Percentage of new and previously treated TB cases that have MDR-TB:

Globally, $3.6 \%$ of new TB cases and $20.2 \%$ of previously treated TB cases are estimated to have MDR-TB.

- Estimated global incidence of MDR-TB and estimated number of MDR-TB cases among notified TB patients: 


\begin{tabular}{|c|c|c|}
\hline & Number (Millions) & Rate/100,000 Persons \\
\hline Incidence & 2.3 & 185 \\
\hline Prevalence & 3.1 & 256 \\
\hline Mortality & 0.32 & 26 \\
\hline
\end{tabular}

Globally, there were an estimated 300,000 MDR-TB cases among notified TB patients in the year 2012.

HIV and tuberculosis ${ }^{1,4,5}$

Tuberculosis and HIV are the infectious diseases causing the maximum number of deaths globally after malaria.

\section{Prevalence in India ${ }^{2}$}

- In India, MDR-TB among notified pulmonary TB patients has been estimated to be 0.064 millions in the year 2011.

Maximum cases of MDR tuberculosis have been reported to arise from populous Asian countries such as China, India, the Philippines, and Indonesia. ${ }^{6}$

\section{Classification of Drug resistance TB (DR-TB)}

Drug resistance can be categorized into three classes on the basis of the history of previous TB treatment. ${ }^{3}$

1. Resistance in new patients (previously called 'primary resistance')

This type of resistance occurs in the patients with no history of previous TB treatment or patients who have received TB treatment for $<1$ month previously.

2. Resistance in previously treated patients(previously called 'acquired resistance')

It refers to resistance with one or more previous TB treatment episodes, of $>1$ month each. Cases of these types are also called as re-treatment cases.

\section{Resistance levels in re-treatment}

The re-treatment resistance levels are always higher than resistance in new patients. This provides a measure of the degree to which patients were properly treated.

Rationale for the Development of Drug-Resistant TB The basis of resistance to TB drugs is the ability of the M. tuberculosis to undergo spontaneous and slow but constant mutations resulting in resistant mutant organisms. This genetic alteration is a naturally occurring phenomenon and varies from drug to drug., ${ }^{3,5}$ The frequency of spontaneous resistance to first-line anti-TB drugs is as follows:

Isoniazid: 1 in every $10^{6}$ cell divisions Rifampicin: 1 in every $10^{9}$ cell divisions Streptomycin: 1 in every $10^{6}$ cell divisions Ethambutol: 1 in every $10^{5}$ cell divisions Pyrazinamide: 1 in every $10^{5}$ cell divisions
Erroneous TB treatment with first-line drugs like prescription of inadequate drugs, programme failure with high treatment non-compliance and default can result in the emergence of MDR-TB.

\section{Risk Factors}

The following are special risk factors for MDR tuberculosis: $:^{1-3}$

- Previous anti-tuberculosis therapy

- Immigration from an area with high prevalence of MDR-TB

- Contact with MDR-TB patients

- HIV infection

- Imprisonment

Factors promoting the development of resistance ${ }^{5}$

- Malabsorption

- Drug intolerance

- Drug interactions

\section{EXTENSIVELY-DRUG RESISTANT TB (XDR-TB)}

Extensively drug resistant TB (XDR-TB) is an uncommon form of tuberculosis, defined as MDR-TB with additional resistance to fluoroquinolones and at least one of the injectable second-line drugs (AMK, CAP or KAN). ${ }^{7}$

\section{Prevalence of XDR-TB}

\section{Global Prevalence of XDR-TB}

Globally, 9\% of patients with MDR-TB have been reported to have XDR-TB.

2. Indian Scenario ${ }^{8}$

Recently it has been reported that $3.7 \%$ were XDR-TB cases among 483 MDR-TB cases, most of which were previously treated.

\section{MECHANISMS OF ACTION AND RESISTANCE OF DIFFERENT ANTI-TB DRUGS}

Anti-TB drugs are generally categorized into two types: old and new anti-tuberculosis agents. Given below is an updated review of the mechanisms of action and resistance of these drugs so as to provide an insight for proper management strategies for patients suffering from the disease.

\section{Conventional TB Drugs}

\section{Isoniazid(INH)}

Mechanism of action

Isoniazid (isonicotinic acid hydrazide, INH) is a pro-drug, which involves oxidative activation by KatG (catalaseperoxidase) enzyme of $M$. tuberculosis. The drug acts by inhibiting mycolic acid synthesis pathway of mycobacteria. 
The activated form of the drug binds by a covalent linkage to the NADH-dependent enoyl acyl carrier protein (ACP) reductase InhA(a component of the fatty acid synthase II system of mycobacteria), which is crucial for fatty acid elongation. ${ }^{9}$

\section{Mechanism of resistance}

Mostly mutations in INH-resistant clinical isolates occurs in $\mathrm{KatG}$ gene (in $50-80 \%$ of cases), therefore impairing the ability of the catalase- peroxidase to activate the INH pro-drug.

A single point mutation in KatG gene (substitution of threonine for serine at residue 315 (S315T)) occurs which results in a considerable reduction in catalase and peroxidase activity, and is associated with high-level INH resistance (minimum inhibitory concentration-MIC = $5-10 \mu \mathrm{g} / \mathrm{mL}){ }^{10}$

Mutations in InhA may also confer INH resistance. Consequently, there is reduced affinity of the enzyme for $\mathrm{NADH}$ without affecting its enoyl reductase activity. ${ }^{11}$

\section{Rifamycins (Rifampicin-RIF) Mechanism of action}

Rifamycins act by inhibiting transcription by binding with high affinity to bacterial DNA-dependent RNA polymerase. $^{9}$

\section{Mechanism of resistance}

Resistance to RIF occurs mostly as single point mutations in the rpoB gene (encoding the $\beta$-subunit of RNA polymerase) with a frequency of $10^{-7}$ to $10^{-8}$ organisms. ${ }^{12} 90 \%$ of RIF-resistant clinical isolates show point mutations cluster in an 81 -base pair region between codons 507 and 533 of the rpoB gene("hot-spot" region). The mutations preponderate in codons 531 [Ser] and $526[\mathrm{His}] .^{13}$

\section{Pyrazinamide (PZA) Mechanism of action}

Like INH, PZA also exists in its pro-drug form and requires activation to its active form, pyrazinoic acid (POA), by the action of enzyme pyrazinamidase (PZase). ${ }^{14}$ It shows anti-tuberculosis activity by disrupting the proton motive force required for essential membrane transport functions by POA at acidic $\mathrm{pH} .{ }^{15}$

\section{Mechanism of resistance}

PZA resistance occurs mainly due to mutations in the pncA gene encoding PZase. Mutations including point mutations, deletions, and insertions, have been reported in a 561-bp region of the open reading frame (ORF) or in an 82-bp region of its putative promoter. ${ }^{14,16}$

\section{Ethambutol (EMB)} Mechanism of action

EMB primarily affects arabinogalactan biosynthesis through inhibition of cell wall arabinan polymerization. ${ }^{17}$ Besides, EMB has also been reported to inhibit some other cellular pathways like RNA metabolism, mycolic acids transfer into the cell wall, phospholipid synthesis and spermidine biosynthesis. ${ }^{9}$

\section{Mechanism of resistance}

Resistance to EMB is mainly due to point mutations in the embCAB operon particularly embB. ${ }^{18}$

\section{Aminoglycosides Mechanism of action}

Aminoglycosides are used currently as second-line drugs primarily in the treatment of MDR-TB. Some examples of aminoglycosides having antimycobacterial activity are streptomycin, kanamycin and amikacin. Aminoglycosides acts by inhibiting translation process in mycobacterial species by binding to the $30 \mathrm{~S}$ ribosomal subunit.'

\section{Mechanism of resistance}

Mutation of the ribosome target binding sites contributes to resistance to streptomycin and the other aminoglycosides in $M$. tuberculosis. Approximately 50\% of the clinical isolates show mutations in the rpsL gene (encoding the ribosomal protein S12) with the K43R mutation predominating. ${ }^{19}$ Besides, about 20\% of streptomycin-resistant clinical isolates show drug resistance due to mutations in the rrs gene (clustered in the regions adjacent to nucleotides 530 or 912). Recently, it has been shown that mutations in gidB gene (encoding a conserved S-adenosylmethionine-dependent $16 \mathrm{~S}$ rRNA methyltransferase) also confers low-level resistance to streptomycin. ${ }^{20}$

\section{Fluoroquinolones}

The fluoroquinolones are presently used as second-line drugs in TB treatment. This class of anti-TB drugs show exceptional antimycobacterial acivity. Some common fluoroquinolones used to treat tuberculosis are moxifloxacin, gatifloxacin, sparfloxacin, levofloxacin, ofloxacin, and ciprofloxacin.

\section{Mechanism of action}

Fluoroquinolones display their strong antibacterial activity by trapping gyrase and topoisomerase IV on DNA as ternary complexes which results in blockade of the movement of replication forks and transcription complexes. ${ }^{21}$ Topoisomerase IV is absent in M. tuberculosis, but the genes gyrA and gyrB encoding the $\mathrm{A}$ and $\mathrm{B}$ subunits of DNA gyrase respectively are present. $^{22}$ 


\section{Mechanism of resistance}

The main mechanism of fluoroquinolone resistance are the mutations in the conserved quinolone resistancedetermining region (QRDR) of gyrA and gyrB which relates between the drug and DNA gyrase. ${ }^{23}$ High-level resistance to fluoroquinolones normally occurs when there are multiple mutations in gyr A, or concurrent mutations in gyrA and gyrB. ${ }^{24}$ Mutations at positions Ala-90 and Asp-94 in the gyrA gene are most frequent. ${ }^{25}$

\section{Macrolides (Clarithromycin) Mechanism of action}

Macrolides exhibit their antibacterial effect by binding to the bacterial $50 \mathrm{~S}$ ribosomal subunit and inhibiting RNAdependent protein synthesis. ${ }^{26}$

\section{Mechanism of resistance}

Resistance to the macrolides occurs due to low cell wall permeability and expression of the erm(37) gene encoding a $23 \mathrm{~S}$ rRNA methyltransferase, which is present in all members of the $M$. tuberculosis complex. ${ }^{27}$

\section{Ethionamide Mechanism of action}

Ethionamide occurs in pro-drug form requiring activation by the monooxygenase EthA. Like INH it also inhibits mycolic acid synthesis by binding the ACP reductase InhA. ${ }^{28}$

\section{Mechanism of resistance}

Seventy-five percent of $M$. tuberculosis isolates have mutations in ethA or inhA. ${ }^{29}$ Besides, defective mycothiol biosynthesis by $M$. tuberculosis mshA deletion mutants also contributes to ethionamide resistance probably due to defective activation of the drug. ${ }^{30}$

\section{Capreomycin}

\section{Mechanism of action}

The primary mode of action of capreomycin is inhibition of protein synthesis through modification of ribosomal structures at the $16 \mathrm{~S}$ rRNA. ${ }^{31}$

\section{Mechanism of resistance}

Resistance to capreomycin has been connected with mutations in the rrs gene encoding $16 \mathrm{~S}$ rRNA. ${ }^{32}$

\section{Cycloserine}

Mechanism of action

It suspends peptidoglycan synthesis by inhibiting the enzymes d-alanine racemase (AlrA) and d-alanine:d-alanine ligase $(\mathrm{Ddl}) .^{33}$

\section{Mechanism of resistance}

The mechanism by which cycloserine exhibits resistance are not clearly known however it has been reported that overexpression of $M$. tuberculosis AlrA and Ddl on a multicopy vector results in resistance to D-cycloserine in M. smegmatis and $M$. bovis BCG. ${ }^{34}$

\section{Paraaminosalicylic acid(PAS) Mechanism of action}

PAS is thought to act by inhibiting folic acid biosynthesis and uptake of iron. ${ }^{31}$

\section{Mechanism of resistance}

Mutations in the thy A gene encoding the enzyme thimidylate synthesis of the folate biosynthesis pathway confer PAS resistance in $M$. tuberculosis. ${ }^{35}$ Thr202Ala has been found to be common mutation associated with PAS resistance. ${ }^{36}$

\section{Novel TB drugs}

A number of novel drugs have emerged recently as potential candidates for the treatment of TB. Their mechanism of action is distinctive from that of the classical anti-TB drugs and thus used to treat MDR-TB.

\section{Nitroimidazoles}

One of the vital microenvironmental conditions encountered by persistent bacilli within necrotic lung granulomas in the human host is reduced oxygen tension. As a result, the bacilli become susceptible to metronidazole a nitroimidazole drug used to treat anaerobic infections. Metronidazole, requires activation by the pyruvate: ferredoxin oxidereductase system under anoxic conditions. Examples of nitroimidazoles which show antimycobacterial activity are PA-824 and OPC-67683. ${ }^{9}$

\section{PA-824}

\section{Mechanism of action}

PA-824 has been shown to display bactericidal activity against actively multiplying and non-replicating bacilli. It is a pro-drug requiring reductive activation of an aromatic nitro group to exhibit its antitubercular activity. This requires an F420-dependent glucose-6-phosphate dehydrogenase encoded by Rv0407 (fgd1) and deazaflavin-dependent nitroreductase (Ddn) encoded by Rv3547. The bactericidal activity of PA-824 is attributed to the formation of the desnitroimidazole metabolite of PA-824 which is considered to generate reactive nitrogen species like nitric oxide. ${ }^{37,38}$

\section{Mechanism of resistance}

Mutations in the genes Rv0407 and Rv3547 (which encode for the activating enzymes) that leads to loss of pro-drug activation.

\section{OPC-67683(Delamanid)}

\section{Mechanism of action}

OPC-67683 is a pro-drug requiring reductive activation by M. tuberculosis. The drug inhibits the synthesis of methoxyand keto-mycolic acids. ${ }^{?}$ 


\section{Mechanism of resistance}

Similar to that of PA-824, defective activation of the drug due to mutations in the Rv3547 gene is the basis of resistance of OPC-67683. ${ }^{39}$

\section{TMC207(Bedaquiline) Mechanism of action}

TMC207 (R207910 or "J compound") is a first-in-class antiTB diarylquinoline which show bactericidal and sterilizing activities against drug-susceptible and drug-resistant $M$. tuberculosis in vitro and in animal models. TMC207 acts by inhibiting a principal enzyme ATP synthase required for synthesis of ATP for $M$. tuberculosis ${ }^{40,41}$

\section{Mechanism of resistance}

Resistance to TMC207 is considered due to mutations in the atpE gene encoding the transmembrane and oligomeric C subunit of ATP synthase ${ }^{42}$ though more recent studies have reported that maximum number of mutants resistant to TMC207 lacked mutations in atpE. This indicates the existence of alternative drug resistance mechanisms. ${ }^{9}$

\section{Oxazolidinones}

Oxazolidinones are a new chemical class of synthetic antibiotics which act by inhibiting of protein synthesis. Examples of oxazolidinones which show antitubercular activity are linezolid, PNU-100480 and AZD5847.?

\section{Linezolid}

\section{Mechanism of action}

Linezolid is the first compound belonging to the oxazolidinone class generally used to treat drug resistant TB. It is active against intracellular bacilli and acts by binding to the ribosomal $50 \mathrm{~S}$ subunit and thus inhibiting an early step in protein synthesis. ${ }^{43}$

\section{Mechanism of resistance}

Mutations at G2061T and G2576T in the 23S rRNA gene have been reported in in vitro-selected mutants which showed high resistance to linezolid (MIC $=16-32 \mathrm{mg} / \mathrm{L}) .{ }^{44}$

\section{PNU-100480}

PNU-100480 is another effective oxazolidinone having MIC of PNU100480 half that of linezolid. Studies have demonstrated that combination of PNU-100480 to the standard first-line regimen of rifampin, INH, and PZA can decrease the duration of treatment necessary to prevent relapse. $^{45}$

\section{AZD5847}

AZD5847 shows its bactericidal activity against $M$. tuberculosis in macrophages. Recent phase I trials have shown that oral administration of the drug up to $800 \mathrm{mg}$ bid for 14 days was well tolerated in healthy volunteers. Though bioavailability decreases with increasing dose but this effect can be considerably reduced if taken within 2 hours of meals, and the exposures achieved in man correspond to efficacious exposures in the mouse model of TB infection. ${ }^{46}$

\section{Ngeranyl-N'-(2-adamantyl)ethane-1,2-diamine (SQ109)}

SQ109, a novel drug has been found to be an effective treatment for TB together with MDR-TB. The clinical studies show the drug's ability to augment the treatment of TB during the first 2 months of intensive therapy and also to treat MDR-TB. ${ }^{47}$ Whether upregulation of ahpC expression plays role for resistance to SQ109 is yet to be determined. $^{48}$

\section{Phenothiazines}

One of the classical example of the phenothiazine drug which has been reported to have bactericidal activity against drug-susceptible and drug-resistant $M$. tuberculosis in macrophages is the antipsychotic druig thioridazine. ${ }^{49}$ Thioridazine has been shown to effectively cure patients with XDR-TB in Argentina and as salvage therapy in similar patients in India. ${ }^{50}$ The mode of action of thioridazine together with inhibition of type II NADH:menaquinone oxidoreductase as a phenothiazine involves its effect on enzymes of fatty acid metabolism and membrane proteins, particularly efflux pumps. ${ }^{51,52}$

\section{Benzothiazinones (BTZs)}

The 1,3-benzothiazin-4-ones (BTZs) are a new class of drugs showing activity against $M$. tuberculosis in vitro, ex vivo, and in murine TB models. ${ }^{9}$ BTZs act by inhibiting the enzymatic activity of decaprenylphosphoryl- $\beta$-Dribose 2'-epimerase (DprE1) enzyme thus eliminating the formation of decaprenylphosphoryl arabinose, a key precursor required for the synthesis of the cell-wall arabinans, thus causing bacterial lysis and death. ${ }^{53}$

\section{Management strategies for MDR/XDR-TB}

Treatment of MDR-TB and XDR-TB is more complicated than that of susceptible TB. For treatment of MDR-TB and XDR-TB second-line drugs which are less efficient are usually required because first line drugs like isoniazid and rifampin cannot be used. Because of less potency of second line drugs more quantity of them are needed for a long durations. ${ }^{54}$ Table 2 gives the list of the drugs used to treat MDR-TB.

The most common principles used to treat MDR-TB are as follows:

1. Treatment by any first line agent to which susceptibility has been reported. ${ }^{5}$

2. Introduce an injectable drug for a minimum of 6 months of negative cultures. ${ }^{55}$ 


\begin{tabular}{|c|c|c|c|c|}
\hline \multirow{2}{*}{$\begin{array}{l}\text { Group } 1 \\
\text { First line } \\
\text { oral drugs }\end{array}$} & \multicolumn{4}{|c|}{ Second-line anti-tuberculosis agents } \\
\hline & $\begin{array}{l}\text { Group } 2 \\
\text { Injectables }\end{array}$ & $\begin{array}{l}\text { Group } 3 \\
\text { Fluoroquinolones }\end{array}$ & $\begin{array}{l}\text { Group } 4 \\
\text { Oral bacteriostatic second line drugs }\end{array}$ & $\begin{array}{l}\text { Group } 5 \\
\text { Drugs with unclear role }\end{array}$ \\
\hline $\begin{array}{l}\text { Pyrazinamide } \\
\text { Ethambutol } \\
\text { Rifabutin }\end{array}$ & $\begin{array}{l}\text { Kanamycin } \\
\text { Amikacin } \\
\text { Capreomycin } \\
\text { Streptomycin }\end{array}$ & $\begin{array}{l}\text { Levofloxacin } \\
\text { Moxifloxacin } \\
\text { Ofloxacin }\end{array}$ & $\begin{array}{l}\text { Para-aminosalicylic acid } \\
\text { Cycloserine } \\
\text { Terizidone } \\
\text { Ethionamide } \\
\text { Protionamide }\end{array}$ & $\begin{array}{l}\text { Clofazimine } \\
\text { Linezolid } \\
\text { Amoxicillin/Clavulanate } \\
\text { Thioacetazone } \\
\text { Imipenem/cilastatin } \\
\text { High dose isoniazid } \\
\text { Clarithromycin }\end{array}$ \\
\hline
\end{tabular}

3. Treatment by fluoroquinolone whenever possible. ${ }^{55}$

4. Addition of other second-line agents to reach a minimum of four or five drugs. ${ }^{55}$

5. In the case of severe parenchymal damage, highgrade resistance or clinically advanced stages, use of strengthening agents with in vitro evidence of antimycobacterial activity. ${ }^{55}$

\section{Consensus statement for management of MDR-TB}

Revised National Tuberculosis Control Programme (RNTCP) has developed national guidelines for scaling up management of MDR-TB. All health care providers (both in public and private sector) need to adhere to the following for the management of MDR-TB:

1. MDR-TB management should be done only at selected health institutions having required experienced medical expertise and availability of diagnostic and treatment facilities. ${ }^{56}$

2. Diagnosis of MDR-TB ${ }^{56}$

- On the basis of history of previous treatment (e.g. smear positive case after repeated treatment courses etc.) and/or close contact to a possible source case confirmatory of having drug-resistant TB

- Diagnosis of MDR-TB should be done in drug resistance suspected cases through culture and drug susceptibility testing(DST) from a qualityassured laboratory.

\section{Analysis of DST results ${ }^{56}$}

- Due to the poor reproducibility, DST results of the $1^{\text {st }}$ line anti-TB drugs pyrazinamide, streptomycin, and ethambutol should be interpreted with care even under optimal laboratory conditions.

- Due to absence of quality-assurance, and lack of standardized methodology DST results of $2^{\text {nd }}$ line anti-TB drugs (fluoroquinolones (ciprofloxacin, ofloxacin, levofloxacin, moxifloxacin, gatifloxacin, sparfloxacin, pefloxacin); kanamycin, amikacin, capreomycin, ethionamide, prothionamide, cycloserine and PAS should be interpreted with great care.

\section{Treatment regimen ${ }^{56}$}

- All significant examination to be performed prior to treatment initiation.

- The standardized regimen as recommended in the national Directly Observed Treatment, Short Course(DOTS)-Plus guidelines should be used [6(9) Km Ofx Eto Cs Z E/18 Ofx Eto Cs E] ${ }^{a}$

- For patients in whom the results of $2^{\text {nd }}$ line DST from a recognized laboratory are available, an individualized regimen may be used after obtaining a detailed history of previous anti-TB treatment

\section{Treatment Duration ${ }^{56}$}

- At least six months of Intensive Phase (IP) should be given which is extended up to 9 months for those who have a positive culture result taken at $4^{\text {th }}$ month of treatment.

- Continuation Phase (CP) should be given for at least 18 months of following the Intensive Phase.

6. Follow-up schedule ${ }^{56}$

- Every month smear examination during IP and at least quarterly during $\mathrm{CP}$

- Culture examination should be done at least at 4 , 6,12, 18 and 24 months of treatment

- Other important examinations should be done.

7. Treatment adherence and support ${ }^{56}$

- Intensive counselling of all patients and their family members prior to and during treatment and all follow-up visits

- To minimize the risk of development of resistance to second-line anti-TB drugs and attain optimal treatment outcomes, administration of treatment under direct observation (DOT) over the entire course of treatment

- If there is unfeasibility of DOT, efforts to ensure treatment adherence should be made by

${ }^{2} 6(9)$ = 6-9 months; $\mathrm{Km}=$ Kanamycin; Ofx=Ofloxacin; Eto $=$ Ethionamide; $\mathrm{Cs}=\mathrm{Cycloserine} ; \mathrm{Z}=$ Pyrazinamide; $\mathrm{E}=$ Ethambutol 
o Checking empty blister packs

o At least monthly follow up visits

\section{Documentation/ Records of treatment ${ }^{56}$}

Health care providers managing MDR-TB patients should maintain a systematic record of treatment regimen, doses, duration, side-effects, investigation results and treatment outcome for all patients initiated on second-line treatment.

\section{Treatment regimens for MDR-TB}

The suggested treatment regimen for confirmed MDR-TB is as follows:

All drugs from Group 1 (pyrazinamide and ethambutol) to which the patient is susceptible, a second-line injectable (from Group 2), a later generation quinolone (moxifloxacin or levofloxacin - from Group 3), and additional drugs from groups 4(ethionamide/prothionamide) and 5 to complete a satisfactory regimen. The injectable agent should be given for at least 7 months, and preferably for at least 4 months beyond when the patient first becomes smear- or culture-negative. ${ }^{54}$

\section{Consensus statement for XDR-TB}

The principles used for treatment of XDR-TB are same to those used for the treatment of MDR-TB, with oral agents prescribed for at least 18 months and injectable drugs prescribed for at least 8 months beyond culture conversion $^{54}$ The latest expert consensus to manage XDRTB is given below:

1. Use any Group 1 agents that may be efficient. ${ }^{57}$

2. Use an injectable agent to which strain is susceptible and consider an extended duration of use (12 months or possibly the whole treatment). In case of resistance to all injectable agents, use one that has never adminstered before. ${ }^{\text {b57 }}$

3. Use a later-generation fluoroquinolone such as moxifloxacin. ${ }^{57}$

4. Use all Group 4 agents that have not been used extensively in a previous regimen or any that are likely to be effective. ${ }^{57}$

5. Use two or more agents from Group $5 .^{57}$

6. High-dose isoniazid treatment should be given if lowlevel resistance is reported. ${ }^{57}$

7. Adjuvant surgery can be taken if there is localized disease. ${ }^{57}$

${ }^{b}$ This recommendation is made because, while the reproducibility and reliability of DST to injectables are good, there are little data on clinical efficacy of the test. Options with XDR-TB are very limited and some strains may be affected in vivo by an injectable agent even though they are testing resistant in vitro.
8. Make sure of strong infection control measures. ${ }^{57}$

9. Treat HIV. ${ }^{57}$

10. Provide comprehensive monitoring and full adherence support. ${ }^{57}$

Key recommendations from WHO guidelines for the programmatic management of DR-TB ${ }^{57,58}$

- At least four second-line antituberculosis drugs likely to be effective as well as pyrazinamide during IP of treatment.

- Use only four second-line anti-tuberculosis drugs in patients with extensive disease (do not add more drugs). Number of second-line drugs can be increased in a regimen if the effectiveness of some of the drugs is uncertain(permitted).

- The regimen should include pyrazinamide, a fluoroquinolone, a parenteral agent, ethionamide (or prothionamide) and cycloserine, or PAS if cycloserine cannot be used.

- Ethambutol may be used but is not included among the drugs making up the standard regimen.

- Group 5 drugs may be used but are not included among the drugs making up the standard regimen.

- Do not use ciprofloxacin as an antituberculosis agent.

\section{REFERENCES}

1. Chapter 2. The burden of disease caused by TB. Global Tuberculosis Report 2013 WHO Library CataloguinginPublication Data. (online) 2013. pp 6-27. Available from URL: WHO/HTM/TB/2013.11.

2. Chapter 3. TB Epidemiology. TB India 2013. Revised National TB Control Programme. Annual Status Report. Central TB division. Directorate General of Health Services.(online) 2013. pp 19-27. Available from URL:http://www.tbcindia.nic.in/pdfs/ tbindia2013.pdf.

3. Chapter 1. Introduction. Management of Drug-Resistant Tuberculosis. Policy guidelines. 2011. Department health: Republic of South Africa. (online) 2013. pp 4-7. Available from URL:http://www.doh.gov.za/docs/policy/2012/TBpolicy. pdf.

4. Chapter 4. Drug-resistant TB. Report 2013 WHO Library Cataloguing-in-Publication Data. (online) 2013. pp 45-58. Available from URL: WHO/HTM/TB/2013.11.

5. Loddenkemper $\mathrm{R}$ and Hauer B. Drug-Resistant Tuberculosis. A Worldwide Epidemic Poses a New Challenge. Dtsch Arztebl Int 2010; 107(11-2): 10-19.

6. Abubakar I, Zignol M, Falzon D, Raviglione M, Ditiu L, Masham $S$ et al. Drug-resistant tuberculosis: time for visionary political leadership. Tuberculosis 2013: 5. 2013; Available from URL: www.thelancet.com/infection. http://dx.doi.org/10.1016/ S1473-3099(13)70030-6.

7. TB Elimination. Extensively Drug-Resistant Tuberculosis (XDR TB). CDC. Extensively Drug-Resistant Tuberculosis Information (online). 2013. Available from URL: http://www.cdc.gov/tb/topic/ drtb/ xdrtb.htm.

8. Porwal C, Kaushik A, Makkar N, Banavaliker JN, Hanif M, Singla $\mathrm{R}$, et al. Incidence and risk factors for extensively drug-resistant tuberculosis in Delhi region. PLoS One.2013; 8:e55299. 
9. Kolyva AS and Karakousis PC. Old and New TB Drugs: Mechanisms of Action and Resistance, Understanding Tuberculosis - New Approaches to Fighting Against Drug Resistance, Dr. Pere-Joan Cardona (Ed.), ISBN: 978-953307-948-6, InTech. 2012; Available from URL: http://www. intechopen.com/books/understandingtuberculosis-newapproaches-to-fighting-against-drugresistance/old-and-new-tbdrugs-mechanisms-ofaction- and-resistance.

10. Abate G, Hoffner SE, Thomsen VO and Miörner $\mathrm{H}$. Characterization of isoniazid-resistant strains of Mycobacterium tuberculosis on the basis of phenotypic properties and mutations in kat G. Eur J Clin Microbiol Infect Dis.2001; 20(5): 329-333.

11. Luiz AB, Renjian Z, James MM, William RJ and John SB. Mechanisms of isoniazid resistance in Mycobacterium tuberculosis: enzymatic characterization of enoyl reductase mutants identified in isoniazid resistant clinical isolates. Journal of Infectious Diseases. 1998; 178(3): 769-775.

12. Telenti A, Imboden P, Marchesi F, Lowrie D, Cole S, Colston MJ et al. Detection of rifampicin-resistance mutations in Mycobacterium tuberculosis. Lancet. 1993; 341(8846): 647-650.

13. Ramaswamy $S$ and Musser JM. Molecular genetic basis of antimicrobial agent resistance in Mycobacterium tuberculosis: 1998 update. Tuber Lung Dis 1998; 79(1): 3-29.

14. Scorpio $A$ and Zhang $Y$. Mutations in pncA, a gene encoding pyrazinamidase/nicotinamidase, cause resistance to the antituberculous drug pyrazinamide in tubercle bacillus. Nat Med 1996; 2(6): 662-667.

15. Zhang $\mathrm{Y}$, Wade MM, Scorpio A, Zhang $\mathrm{H}$ and Sun Z. Mode of action of pyrazinamide: disruption of Mycobacterium tuberculosis membrane transport and energetics by pyrazinoic acid. J Antimicrob Chemother. 2003; 52(5): 790-795.

16. Juréen $P$, Werngren J, Toro JC and Hoffner S. Pyrazinamide resistance and pncA gene mutations in Mycobacterium tuberculosis. Antimicrob Agents Chemother.2008; 52(5): 18521854.

17. Mikusová K, Slayden RA, Besra GS and Brennan PJ. Biogenesis of the mycobacterial cell wall and the site of action of ethambutol. Antimicrob Agents Chemother. 1995; 39(11): 2484-2489.

18. Ramaswamy SV, Amin AG, Göksel S, Stager CE, Dou SJ, Sahly $\mathrm{H} \mathrm{El}$, et al. Molecular genetic analysis of nucleotide polymorphisms associated with ethambutol resistance in human isolates of Mycobacterium tuberculosis. Antimicrob Agents Chemother. 2000; 44(2): 326-336.

19. Cooksey RC, Morlock GP, McQueen A, Glickman SE and Crawford JT. Characterization of streptomycin resistance mechanisms among Mycobacterium tuberculosis isolates from patients in New York City. Antimicrob Agents Chemother. 1996; 40(5): 1186-1188.

20. Wong SY, Lee JS, Kwak HK, Via LE, Boshoff HI and Barry CE 3rd. Mutations in gidB confer low-level streptomycin resistance in Mycobacterium tuberculosis. Antimicrob Agents Chemother. 2011; 55(6): 2515-2522.

21. Drlica $\mathrm{K}$ and Malik M. Fluoroquinolones: action and resistance. Curr Top Med Chem 2003 3(3): 249-282.

22. Cole ST, Brosch R, Parkhill J, Garnier T, Churcher C, Harris D, et al. Deciphering the biology of Mycobacterium tuberculosis from the complete genome sequence. Nature. 1998; 393(6685): 537-544.

23. Ginsburg AS, Grosset JH and Isha WR. Fluoroquinolones, tuberculosis, and resistance. Lancet Infectious Diseases. 2003; 3(7): 432-442.

24. Xu C, Kreiswirth BN, Sreevatsan S, Musser JM and Drlica K. Fluoroquinolone resistance associated with specific gyrase mutations in clinical isolates of multidrug-resistant
Mycobacterium tuberculosis. Journal of Infectious Diseases. 1996; 174(5): 1127-1130.

25. Aubry A, Veziris N, Cambau E, Truffot-Pernot C, Jarlier V and Fisher LM. Novel gyrase mutations in quinoloneresistant and -hypersusceptible clinical isolates of Mycobacterium tuberculosis: functional analysis of mutant enzymes. Antimicrob Agents Chemother. 2006; 50(1): 104-112.

26. Piscitelli SC, Danziger LH and Rodvold KA. Clarithromycin and azithromycin: new macrolide antibiotics. Clin Pharm. 1992; 11(2): 137-152.

27. Buriánková K, Florence Doucet-Populaire $F$, Dorson $\mathrm{O}$, Gondran A, Ghnassia J-C, Weiser J, et al. Molecular basis of intrinsic macrolide resistance in the Mycobacterium tuberculosis complex. Antimicrob Agents Chemother. 2004; 48(1): 143-150.

28. Vannelli TA, Dykman A and Ortiz de Montellano PR. The antituberculosis drug ethionamide is activated by a flavoprotein monooxygenase. J Biol Chem. 2002; 277(15): 12824-12829.

29. Morlock GP, Metchock B, Sikes D, Crawford JT and Cooksey $\mathrm{RC}$. ethA, inhA, and katG loci of ethionamide resistant clinical Mycobacterium tuberculosis isolates. Antimicrob Agents Chemother. 2003; 47(12): 3799-3805.

30. Vilchèze C, Av-Gay Y, Attarian R, Zhen Liu Z, Hazbón MH, Colangeli $R$, et al. Mycothiol biosynthesis is essential for ethionamide susceptibility in Mycobacterium tuberculosis. Mol Microbiol. 2008; 69(5): 1316-1329.

31. Wade MM and Zhang Y. Mechanisms of drug resistance in Mycobacterium tuberculosis. Front Biosci 2004; 9: 975-994.

32. Alangaden GJ, Kreiswirth BN, Aouad A, Khetarpal M, Igno FR and Moghazeh SL. Mechanism of resistance to amikacin and kanamycin in Mycobacterium tuberculosis. Antimicrob Agents Chemother.1998 42(5):1295-1297.

33. Caceres NE, Harris NB, Wellehan JF, Feng Z, Kapur V and Barletta RG. Ove rexpression of the D-alanine racemase gene confers resistance to D-cycloserine in Mycobacterium smegmatis. Journal of Bacteriology. 1997; 179(16): 5046-5055.

34. Feng $Z$ and Barletta RG. Roles of Mycobacterium smegmatis $\mathrm{D}$-alanine: $\mathrm{D}$-alanine ligase and $\mathrm{D}$-alanine racemase in the mechanisms of action of and resistance to the peptidoglycan inhibitor D-cycloserine. Antimicrob Agents Chemother 2003; 47(1): 283- 291

35. Rengarajan $\mathrm{J}$ and Sassetti $\mathrm{CM}$. The folate pathway is a target for resistance to the drug para-aminosalicylic acid (PAS) in mycobacteria. Mol Microbiol 2004; 53(1): 275-282.

36. Leung KL, Yip CW, Yeung YL, KL Wong, WY Chan, Chan MY, et al. Usefulness of resistant gene markers for predicting treatment outcome on second-line anti-tuberculosis drugs. $J$ Appl Microbiol. 2010; 109(6):2087-2094.

37. Stover CK, Warrener P, VanDevanter DR, Sherman DR, Arain $\mathrm{TM}$, Langhorne $\mathrm{MH}$, et al. A small-molecule nitroimidazopyran drug candidate for the treatment of tuberculosis. Nature. 2000; 405(6789): 962-966.

38. Singh R, Manjunatha $U$, Boshoff HIM, Hwan $\mathrm{Ha} Y H$, Niyomrattanakit P, Richard Ledwidge $\mathrm{R}$, et al. PA-824 kills nonreplicating Mycobacterium tuberculosis by intracellular NO release. Science. 2008; 322(5906): 1392-1395.

39. Matsumoto $M$, Hashizume $H$, Tomishige $T$, Kawasaki $M$, Tsubouchi H, Sasaki H, et al. OPC-67683, a nitrodihydroimidazooxazole derivative with promising action against tuberculosis in vitro and in mice. PLoS Med. 2006; 3(11): e466.

40. Zhang T, Li SY, Williams KN, Andries K, Nuermberger EL, et al. Short-course Chemotherapy with TMC-207 and Rifapentine in a Murine Model of Latent Tuberculosis Infection. Am J Respir Crit Care Med.2011.

41. Andries K, Verhasselt P, Guillemont J, Göhlmann HW, Neefs $\mathrm{JM}$, Winkler $\mathrm{H}$, et al. A diarylquinoline drug active on the ATP 
synthase of Mycobacterium tuberculosis. Science. 2005; 307(5707): 223-227.

42. Petrella S, Cambau E, Chauffour A, Andries K, Jarlier V and Wladimir Sougakoff W. Genetic basis for natural and acquired resistance to the diarylquinoline R207910 in mycobacteria. Antimicrob Agents Chemother. 2006; 50(8): 2853-2856.

43. Zhang Y. The magic bullets and tuberculosis drug targets. Annu Rev Pharmacol Toxicol 2005; 45: 529-564.

44. Hillemann D, Ru"sch-Gerdes S and Richter E. In vitro-selected linezolid-resistant Mycobacterium tuberculosis mutants. Antimicrob Agents Chemother. 2008; 52(2): 800-801.

45. Williams KN, Brickner SJ, Stover CK, Zhu T, Ogden A and Tasneen R, et al. Addition of PNU-100480 to first-line drugs shortens the time needed to cure murine tuberculosis. Am J Respir Crit Care Med. 2009; 180(4): 371-376.

46. B. Subramanian. Gordon Research Conference on Tuberculosis Drug Development, July 2011

47. Lalloo UG and Ambaram A. New antituberculous drugs in development. Curr HIVIAIDS Rep 2010; 7(3): 143-151.

48. Jia L, Coward L, Gorman GS, Noker PE and Tomaszewski JE. Pharmacoproteomic effects of isoniazid, ethambutol, and Ngeranyl-N'-(2-adamantyl) ethane-1, 2-diamine (SQ109) on Mycobacterium tuberculosis H37Rv. J Pharmacol Exp Ther. 2005; 315(2): 905-911.

49. Ordway D, Viveiros M, Leandro C, Bettencourt R, Almeida J, Martins $\mathrm{M}$, et al. Clinical concentrations of thioridazine kill intracellular multidrug-resistant Mycobacterium tuberculosis. Antimicrob Agents Chemother. 2003; 47(3): 917-922.

50. Amaral L, Boeree MJ, Gillespie SH, Udwadia ZF and van Soolingen D. Thioridazine cures extensively drug resistant tuberculosis (XDR-TB) and the need for global trials is now! Int $\mathrm{J}$ Antimicrob Agents. 2010; 35(6): 524-526.

51. Dutta NK, Mazumdar, KDastidar SG, Karakousis PC and Amara L. New patentable use of an old neuroleptic compound thioridazine to combat tuberculosis: a gene regulation perspective. Recent Pat Antiinfect Drug Discov. 2011; 6(2): 128-138.

52. Weinstein EA, Yano T, Li L-S, Avarbock D, Avarbock $A$ and Helm D. Inhibitors of type II NADH: menaquinone oxidoreductase represent a class of antitubercular drugs. Proc Natl Acad Sci U S A. $2005 ;$ 102(12): 4548-4553.

53. Makarov V, Manina G, Mikusova K, Möllmann U, Ryabova O, Saint-Joanis B, et al. Benzothiazinones kill Mycobacterium tuberculosis by blocking arabinan synthesis. Science. 2009; 324(5928): 801-804.

54. Pinto $L$ and Menzies $D$. Treatment of drug-resistant tuberculosis. Infection and Drug Resistance 2011; 4:129-135.

55. Furin J. The Clinical Management of Drug-Resistant Tuberculosis. Curr Opin Pulm Med 2007; 13(3):212-217.

56. Multi-drug resistant and Extensively drug resistant TB in India. Consensus statement on the problem, prevention, management and control. 2007. Available from URL. http://www.tbcindia.nic. in/pdfs/Consensus statement on MDR XDRTB-Final.pdf

57. Guidelines for the programmatic management of drug-resistant tuberculosis. Emergency update 2008. WHO. Available from URL: http://whqlibdoc. who.int/publications/2008/9789241547581_ eng.pdf

58. Guidelines for the programmatic management of drugresistant tuberculosis.2011 update. WHO. Available from URL http://whqlibdoc.who.int/publications/2011/9789241501583_ eng.pdf 